\title{
DO FILME AO ROMANCE: ASPECTOS DO PROCESSO DE ADAPTAÇÃO ROMANCEADA
}

\begin{abstract}
André Soares Vieira*
Resumo: Tendo em vista que as relações entre o cinema e a literatura historicamente se constituíram em uma via de mão dupla, este artigo objetiva mapear alguns dos aspectos que permeiam o processo de adaptação romanceada de filmes segundo a perspectiva da tradução intersemiótica. Caberá focalizar a história das transposições cine-literárias, seu percurso desde as origens do cinema, passando pelos cine-romances e romances baseados em filmes. Trata-se aqui de verificar de que modo o escritor consegue criar uma tensão entre os dois âmbitos narrativos (filme e romance) na criação de uma obra literária autônoma dotada de ressonância própria.
\end{abstract}

Palavras-chave: Cinema e literatura; adaptação romanceada; tradução intersemiótica.

Preocupado em elucidar os processos que subjazem à teoria da tradução, Roman Jakobson aponta, em seus Ensaios de lingüística geral, para a existência de três maneiras de interpretar um signo verbal. Trata-se da tradução intralingual, ou paráfrase, que tem lugar no seio da mesma língua; da tradução interlingual, quando um texto verbal é recriado em uma língua diferente e,

* Universidade Federal de Santa Maria / Pós-doutorado na Universidade Federal de Minas Gerais. 
finalmente, da tradução intersemiótica, procedimento de trocas entre sistemas sígnicos distintos, "interpretação de signos verbais por meio de signos não verbais". ${ }^{1}$ Nessa direção, explica que a tradução intersemiótica seria produzida quando, por exemplo, opera-se com transferências da linguagem para a pintura, a dança, a música ou o cinema: óperas transpostas de peças teatrais, filmes adaptados de romances; quadros inspirados em episódios bíblicos. Percebe-se facilmente que Jakobson prevê essa operação em um único sentido, da linguagem verbal às outras artes e meios, esquecendo ou omitindo o percurso inverso da tradução, cujo conceito seria ampliado ao se aplicar a toda e qualquer transposição de um sistema de signos para outro, assim incluindo os movimentos da pintura, da dança, da música e do cinema em direção ao texto verbal.

É indubitável que o processo de adaptação, no sentido percebido por Jakobson como tradução intersemiótica tout court, representa um modo de relação recorrente entre o cinema e a literatura. No entanto, a terceira categoria de tradução, enquanto processo dinâmico de trocas e de transferências entre sistemas de signos, linguísticos ou não, em um sentido mais amplo, não deveria prescindir da análise das interpretações verbais de práticas não verbais.

Os procedimentos de tradução, adaptação e transposição de obras de arte constituídas por signos não verbais - picturais, musicais, etc. - para o texto literário não são novos, mas merecerão uma atenção especial, sobretudo ao final do século XIX, quando a pintura passa a ser o objeto privilegiado de descrições por parte de muitos escritores simbolistas. Diversas pesquisas apontaram igualmente para a transposição de elementos próprios à linguagem musical em romances e poemas. O que aqui nos interessa são os processos que permitiram a tradução intersemiótica de um filme para o sistema romanesco no âmbito da adaptação romanceada.

${ }^{1}$ JAKOBSON. Essais de linguistique générale, p. 78. 
Desde sua primeira infância, a Sétima Arte vem recorrendo aos textos literários em busca de uma forma de arte capaz de apresentar uma narrativa que se desenvolva por meio de imagens em movimento. Assim como escritores e pintores estabeleceram um frutífero trabalho de trocas no final do século XIX em suas lutas pela autonomia dos campos literário e artístico, conforme percebeu Pierre Bourdieu, literatura e cinema revivem, de certo modo, e guardadas suas idiossincrasias, um processo semelhante de colaboração nas duas primeiras décadas do século XX. O recémcriado e polêmico cinema aproxima-se assim do campo literário, já institucionalizado e detentor de uma identidade reconhecida, tentando trazer para as telas obras da literatura universal. Essas primeiras adaptações poderiam representar a possibilidade de mostrar que a mais nova das artes havia finalmente deixado de ser um espetáculo de feira. A partir dos anos 1920, existe um entusiasmo crescente por parte de escritores em estabelecer trocas entre o trabalho literário e o trabalho cinematográfico. Os escritores veem na magia da imagem em movimento uma série de respostas para muitas de suas dúvidas acerca dos novos processos de escritura. Escrita telegráfica, fragmentação da narrativa, diluição da figura do narrador, técnicas do fluxo de consciência, toda uma série de procedimentos que poderiam ter sido tomados de empréstimo à linguagem cinematográfica, ou nela se inspirado, passam a fazer parte do processo de criação literária, aprimorandose ao longo do século XX. Os surrealistas, por exemplo, reconhecerão no cinema a mais pura forma de expressão de imagens oníricas do inconsciente.

Durante o período que caracterizou o chamado cinema narrativo hollywoodiano, a partir de 1914, impera o conceito de montagem invisível, na qual a continuidade é realçada e o corte, neutralizado. É o auge da intenção ilusionista, herança direta da narrativa tradicional realista sobre a qual o cinema dos primeiros tempos se apoia, sobretudo com os filmes de Griffith. O espectador tende a ser absorvido pelo sistema formal que procura apagar os traços que o denunciariam como discurso trabalhado: uma espécie 
de "cinema-janela", que tenta captar uma autenticidade objetiva do real. É nesse sentido que a imagem é vista como a vida, e o cinema como janela aberta para o mundo.

Esta concepção de cinema talvez tenha representado um dos primeiros embates opondo escritores e cineastas. Como dito anteriormente, em seus primeiros tempos, a fim de se firmar como arte, o cinema apela à literatura, seja pela transposição de elementos da linguagem romanesca, seja pelas primeiras adaptações de obras literárias. É a passagem do cinematógrafo para o cinema. No entanto, o modelo de narrativa recuperada pelos diretores e roteiristas hollywoodianos dos primeiros tempos não mais correspondia ao que já vinha sendo feito em termos de experimentação com a linguagem em literatura. Em 1922, por exemplo, surge o Ulisses, de James Joyce, obra extremamente inovadora do ponto de vista formal e, para muitos críticos, um divisor de águas na história do romance. O cinema, por seu turno, buscava modelos literários que oferecessem suporte à narrativa fílmica a partir de romances realistas dos Novecentos. Entretanto, em literatura, desde as últimas décadas do século XIX e durante os primeiros decênios do século XX, diversos escritores já colocam em dúvida o antigo modelo real-naturalista, apostando em novas formas de escritura em que a noção de real passa a ser questionada e, com ela, a intenção de dizer, reproduzir e representar o mundo.

Tal como ocorrera nas relações entre a pintura e a literatura, quando, passado o momento eufórico das trocas e diálogos, os pintores começam a perceber a necessidade em se afastar do campo literário em busca de uma pureza das diferenças que definisse o trabalho artístico, também o cinema passa a se preocupar com a busca de uma especificidade definidora de sua linguagem. Por volta de 1928, Eisenstein passa a conceber um modo especial de montagem, agora tornada visível. As disjunções e descontinuidades são realçadas, o que vem a relativizar o caráter ilusionista da narrativa cinematográfica. Para o teórico e cineasta russo, o cinema é, antes de tudo, a montagem. Com Eisenstein, a linguagem do cinema vem se aproximar dos novos experimentos 
com a linguagem literária, já em voga nas duas primeiras décadas do século. Conforme observou Haroldo de Campos, a montagem eisensteiniana seria vista como uma sucessão de imagens fragmentárias ordenadas, de cuja sequência ou colisão surgiria uma nova imagem, maior do que as imagens separadas ou diferente delas. Para as vanguardas históricas do início do século passado, a montagem caracterizou-se como forma de articular signos, sentenças e sequências na fragmentação e na simultaneidade, justapondo e relacionando elementos heterogêneos sem ligação direta entre os mesmos. Na literatura, o uso de formas de montagem veio revelar um processo operador de fragmentos que se apoia no corte e faz fluir múltiplas direções significantes. É o caso de Ulisses que, de certo modo, remete ao padrão de montagem concebido por Eisenstein, para quem a obra de Joyce parecia feita sob medida para a aplicação de sua teoria da montagem. Com Eisenstein, o cinema parece retomar o caminho do diálogo com a literatura, agora em sintonia com os experimentos literários da época.

Os novos experimentos com a linguagem literária, que deverão dominar o século XX, são em grande medida tributários dessa nova visão do tempo e do espaço proporcionada pelo advento do cinema. É a literatura indo ao encontro de elementos da linguagem fílmica, sobretudo a partir dos conceitos de montagem previstos por Eisenstein. Trata-se de uma estética que irá valorizar o corte, a fragmentação da narrativa, bem como a descontinuidade inerente ao corte, forma considerada eficaz para substituir a narrativa linear realista. Em suas lutas para romper com as antigas convenções de representação, o romance moderno apelará ao cinema para dar vida às impressões de movimento e descontinuidade.

Após essa onda de entusiasmo pela ideia de diálogos e trocas entre o trabalho literário e o trabalho cinematográfico, os escritores passam a ver com desconfiança, sobretudo a partir da criação do cinema falado, as relações entre as duas formas de expressão. Os meios literários passam, então, a hostilizar a produção cinematográfica, vista agora como mero plágio canhestro de obras literárias com o objetivo de difundi-las comercialmente. 
Com o fim da Segunda Grande Guerra, instaura-se outra etapa, em que os antagonismos entre cinema e romance mostramse ultrapassados com um novo modo de colaboração entre escritores e cineastas. Alain Robbe-Grillet e Marguerite Duras entre os primeiros, e Alain Resnais, entre os últimos, constituem exemplos significativos, não mais da noção de influência, conforme percebeu Jeanne-Marie Clerc, mas de "osmose" original entre os dois meios de expressão. Tal reconciliação entre o romance e o cinema exigirá, por outro lado, que os escritores passem a trabalhar também atrás das câmeras, buscando adaptar para a tela textos escritos para serem lidos. ${ }^{2}$ Jean Cocteau e Jean Giono transpuseram, eles mesmos, seus romances ou peças teatrais para o cinema, em um percurso da palavra às imagens por meio de textos que se situam a meio caminho entre uns e outros - os roteiros.

Nessa perspectiva, também o romance do século XX será caracterizado pela frequência da representação visual. Trata-se, com efeito, de uma nova sistemática, o que permite verificar nos mais diversos romances a presença de uma visualidade diferente daquela realizada pelo romance realista do século anterior.

$\mathrm{Na}$ esteira desse processo de influência e de adaptações, cabe salientar o trabalho inverso empreendido por romancistas que, a exemplo de Marguerite Duras ou de Alain Robbe-Grillet, publicaram textos inicialmente produzidos para a realização cinematográfica: roteiros ou, como o próprio Robbe-Grillet os batizou, ciné-romans. Para Clerc, a questão que se impõe é a de saber qual a legibilidade destes textos escritos para as imagens no momento em que são privados de seu acompanhamento icônico. Consequentemente, importa saber por quais transformações eventualmente passou o texto para que fosse levado à publicação. Não se trata mais de apenas confrontar duas formas de arte (cinema e literatura), mas de permanecer no domínio da escrita e

${ }^{2}$ CLERC. La littérature comparée devant les images modernes: cinéma, photographie, télévision, p. 266. 
de vislumbrar o modo como esta atesta as marcas de uma visualidade ligada às tecnologias icônicas. Assim, o problema da investigação comparatista que se quer literária é o de saber de que forma o escrito "diz" o visual, e não o modo como o escrito "corresponde" ao visual, segundo uma leitura subjetiva.

No caso específico de traduções, adaptações romanceadas, cine-romances e transposições literárias de filmes, estamos diante de uma categoria de texto que somente em meados do século XX começa a merecer alguma atenção por parte de crítica, escritores e público, a partir do momento em que alguns escritores passam a realizar seus próprios filmes ou, quando menos, a exercer um trabalho de colaboração com cineastas que dirigem seus roteiros. No entanto, já em 1936, Albert Thibaudet lançava as bases para uma reflexão que mais tarde se faria imprescindível sobre as relações entre o cinema e a literatura. Thibaudet, que já percebia a larga contribuição legada pelo cinema silencioso ao romance e ao teatro (movimento, dinamismo, substituição da pantomima pelo diálogo, etc.), inquietava-se pela ausência de uma "literatura do cinema", apta a rivalizar com os filmes sem, no entanto, se apresentar como simples roteiro publicado e, portanto, com valor literário. Embora tecendo também alguns comentários vistos hoje como ingênuos no que diz respeito aos laços que unem as duas formas de expressão, em uma época em que o teatro ainda era a forma mais aproximada da Sétima Arte, Thibaudet foi certamente um dos primeiros críticos a se preocupar com a necessidade de se transpor filmes para o romance, conforme assinalou Etienne Fuzellier:

Mas então, como explicar que a tela não tenha criado sua própria literatura? Teremos um dia, pergunta-se Thibaudet, uma "brochura" de filme que apresente valor literário? Ou teremos para sempre roteiros dialogados como os libretos de uma ópera? ${ }^{3}$

${ }^{3}$ FUZELLIER. Cinéma et littérature, p. 11-12. (tradução nossa) 
A questão da adaptação inversa, ou seja, das imagens às palavras, adquire força em meados dos anos 1960, no rastro dos experimentos sobre a escritura levados a cabo pelo novo romance francês. Se, até então, o livro precedia normalmente o filme, uma evolução inversa começa a se esboçar: escritores passam a adaptar um romance de um filme, e o público passa a encontrar nas livrarias publicações dos textos produzidos para o cinema, no mesmo formato e coleção dos textos literários.

Para Étienne Fuzellier, não se trata mais de relações e influências que podem ser exercidas pela literatura no cinema, mas justamente o inverso: romances que se apresentam como filmes e que, portanto, sofreram uma influência direta do cinema, mas que não possuem em princípio nada a ensinar ou sugerir à arte cinematográfica. Fuzellier quer assim sublinhar a autonomia dos textos adaptados do cinema.

Segundo Alain Virmaux, não é o fato de Robbe-Grillet e Duras serem escritores consagrados que assegura automaticamente um crédito a mais aos textos advindos do cinema, o que poderia justificar o interesse que os mesmos passam a despertar, pois diversos escritores contemporâneos empreenderam tarefa semelhante, $\mathrm{o}$ que não impediu que tais textos caíssem no esquecimento. Com efeito, para que um cine-romance ou a adaptação de um filme mantenham desperta a atenção de forma duradoura, sobreviva aos primeiros comentários superficiais quando de seu lançamento, obtendo alguns olhares da crítica, é necessário que responda a uma exigência simples e, no entanto, raramente preenchida: a de dispor de uma ressonância própria, rivalizando de maneira eficaz com a ressonância do filme. "Se ele for facilmente eclipsado pelo brilho deste último, não oferecendo uma dimensão estética capaz de resistir ao impacto das imagens, certamente estará fadado à extinção em um curto espaço de tempo". ${ }^{4}$

\footnotetext{
${ }^{4}$ VIRMAUX. Le cine-roman: un genre nouveau, p. 80. (tradução nossa)
} 
Ao final dos anos 1950, o diretor Jacques Tati propõe ao editor Robert Laffont uma espécie de concurso. Tati pedia aos jovens escritores de Laffont que escrevessem um capítulo sobre seus filmes Les vacances de Monsieur Hulot (As férias do Sr. Hulot) e Mon oncle (Meu tio, este ainda em fase de filmagens). O ganhador, a ser escolhido pelo próprio Tati, escreveria o restante da adaptação romanceada e seria publicado por Laffont. Dentre os escritores encontrava-se o futuro diretor e roteirista Jean-Claude Carrièrre, então com 25 anos, e que acabara de publicar seu primeiro romance. Carrière vence a competição e escreve as adaptações de ambos os filmes de Tati.

Em seu livro A linguagem secreta do cinema, Carrière conta que já em seu primeiro encontro com Jacques Tati, este o introduz no universo do cinema mostrando-lhe como se faz um filme:

Com instinto certeiro, num espaço de três ou quatro minutos, Tati acabara de me dar a primeira grande lição: para lidar com cinema, sob qualquer ângulo mesmo que seja apenas escrever um livro baseado num filme - você deve saber como os filmes são feitos; você deve conhecer, e de preferência dominar, as técnicas cinematográficas. Você não pode presumir, com indiferença literária, que não é necessário conhecer essa miscelânea de equipamentos especializados e práticas industriais de fundo de quintal. Pelo contrário. Você deve dominar essas práticas, conviver com elas, agarrar-se a elas. ${ }^{5}$

As considerações de Carrière parecem confirmar as teses de Virmaux sobre a necessidade de a obra adaptada de um filme possuir uma ressonância própria, uma dimensão estética que a defina como texto literário e não apenas como mera transcrição de imagens. Ao contrário do que encontraremos, por exemplo, nos textos para o cinema de Duras, nos quais são justamente

${ }^{5}$ CARRIÈRE. A linguagem secreta do cinema, p. 145. 
valorizadas as insuficiências do processo de inserção da imagem no texto com o objetivo de desestabilizar a representação, trata-se aqui de se criar as condições que permitam o estabelecimento de uma narrativa capaz de rivalizar com a ressonância do filme-fonte. Estamos, portanto, diante de um processo de tradução intersemiótica por excelência, através do qual fica evidenciada a autonomia do texto traduzido segundo a perspectiva da tradução como (re)criação.

Para tanto, conforme percebeu Jean-Claude Carrière, não basta ser um escritor para adaptar uma obra fílmica à linguagem literária; é imprescindível dominar as técnicas que subjazem ao processo de criação de um filme. Só assim será possível resistir ao impacto das imagens, como observou Virmaux.

No caso das adaptações de Les vacances de Monsieur Hulot e de Mon oncle, Jean-Claude Carrière opta pelo emprego da primeira pessoa, escolha que já define o caráter propriamente literário dos textos. Em Mon oncle, o narrador é o sobrinho de Monsieur Hulot, um menino de aproximadamente nove anos de idade que conta as aventuras de seu excêntrico e engraçado tio. Carrière parte assim do princípio que norteia a história do filme a partir do próprio título, em primeira pessoa. Curioso notar que no filme de Tati não existe propriamente um narrador. Apesar do titulo, o filme não parece se preocupar em fixar um ponto de vista a partir do qual a história seria contada: não há evidências formais que comprovem a visão do garoto sobre os fatos. Esses parecem ser apresentados segundo uma focalização externa ou ainda heterodiegética.

O caráter homodiegético da narrativa de Carrière confirma a tese segundo a qual "la spécificité romanesque semble donc se

\footnotetext{
${ }^{6}$ CLERC. Littérature et cinéma, p. 99."A especificidade romanesca parece então se concentrar nesta elaboração de uma personagem autônoma, o narrador, e de seu discurso próprio, que serve de mediador absoluto à história tomada de empréstimo ao filme." (tradução nossa)
} 
concentrer dans cette élaboration d'un personnage autonome, le narrateur, et de son discours propre, qui sert de médiateur absolu à l'histoire empruntée au film". ${ }^{6}$ Nesse sentido, ainda segundo Clerc, a adaptação romanceada, recusando-se a usufruir das facilidades miméticas oferecidas pelo filme para a produção de um texto fundado na aproximação imediata com a imagem original, busca encontrar, ao contrário, a pureza da narrativa que mais se afasta da analogia icônica.

No entanto, no caso específico de Mon oncle, as imagens estarão presentes na edição romanceada do filme. Trata-se das ilustrações de Pierre Étaix, responsável pela cenografia do filme de Tati, que estabelecem mais uma mediação com o filme segundo uma perspectiva intermidiática e remetem ao próprio storyboard do filme.

Outra questão que normalmente subjaz ao processo de adaptação literária de um filme diz respeito à necessidade em se recorrer à análise psicológica para enfrentar a insuficiência da linguagem em mostrar o que a imagem apresenta sob forma de espetáculo coletivo dominado pelo movimento. Com efeito, imagem e palavra constituem duas modalidades diferentes da narrativa, duas formas distintas de apreensão do mundo. Em filmes caracterizados por cenas e planos em que as imagens se sobrepõem às palavras, chegando mesmo a dispensá-las, faz-se necessário o apelo aos estados de consciência vivenciados pelo sujeito narrador. É a partir desse ponto de vista intelectual que o escritor poderá traduzir em palavras aquilo que, em imagens, parece refratário à linguagem verbal.

A pantomima, frequentemente utilizada nos filmes de Jacques Tati, encontra no cinema, capaz de mostrar sem a necessidade de dizer, um veículo apropriado. A mera descrição em palavras dos atos pantomímicos dificilmente despertaria no leitor o mesmo impacto produzido pelas imagens em movimento, talvez, arrisca Clerc, porque a decupagem do real exija quase sempre a precisão unificadora de um ponto de vista intelectual que tente explicar o mundo. 
Finalmente, as adaptações romanceadas de filmes evidenciam os próprios mecanismos narrativos do romance em suas diferenças com o cinema. O escritor, tal como o espectador, reconstitui seu próprio cinema a partir de um filme que representa o ponto de partida do processo de recriação. Ainda que deva permanecer fiel a um determinado esquema narrativo imposto pelas leis do gênero, nada impede o apelo à invenção de uma profundidade psicológica das personagens. Algumas passagens do filme poderão ser sumarizadas, outras dialogadas, segundo as necessidades específicas do romance. Assim, o verdadeiro herói do romance, tal como é iluminado por esses textos, é o narrador; as personagens existindo apenas na medida em que ele delas dispõe:

De sorte que, ne se pose guère, dans le cas de ces adaptations romancées, la question de savoir à quoi se réfère le romancier en écrivant, au film ou à la réalité à laquelle ces images sont censées ressembler. La seule référence véritable, en dernière analyse, semble bien être l'auteur lui-même et ses impressions de spectateur: c'est elles qu'il tente apparemment de traduire à travers la distance d'un discours où s'affirme avec ostentation sa propre interprétation du film. ${ }^{7}$

Diferentemente do que ocorre no cinema, em que o discurso do narrador se apaga, coincidindo totalmente com a história, e o que conta é a cumplicidade entre o espectador e a história, no romance o que interessa é a conivência estabelecida entre narrador e leitor. Trata-se de uma valorização não daquilo

\footnotetext{
${ }^{7}$ CLERC. Littérature et cinéma, p. 101. "De modo que não mais se impõe, no caso dessas adaptações romanceadas, a questão de saber a que se refere o romancista ao escrever, se ao filme ou à realidade com a qual as imagens deveriam se parecer. A única referência verdadeira, em última análise, parece ser o próprio autor e suas impressões de espectador: são elas que ele aparentemente tenta traduzir por intermédio da distância de um discurso em se afirma com ostentação sua própria interpretação do filme." (tradução nossa)
} 
que o romance mostra ou conta, mas antes da capacidade de se comunicar com o leitor por intermédio de um discurso que exibe sua presença e materialidade. De modo geral, as adaptações de filmes dependem, portanto, das atitudes do escritor frente às tecnologias da imagem, de seu domínio das técnicas inerentes à produção fílmica, bem como de sua capacidade de interpretação criativa dos dados oferecidos pelo texto-fonte.

Ao adaptar uma obra icônica para um sistema verbal, o escritor coloca-se na posição de um espectador que (re)elabora de modo imaginário seu próprio cinema. Dispondo do conhecimento aprofundado dos processos cinematográficos e da importância do papel do espectador é possível obter-se resultados extremamente interessantes na criação de obras literárias que traduzam, elas também, a riqueza das relações e diálogos entre o cinema e a literatura. Tradução intersemiótica por excelência, a adaptação romanceada de filmes, na contramão das pesquisas de Jakobson, ao efetuar um percurso inverso em direção aos sistemas verbais, demonstra mais uma vez a capacidade de o romance assimilar outros gêneros e formas de expressão, garantia de sua renovação.

Résumé: Cet article vise à répertorier quelques-uns des aspects qui imprègnent le processus de novellisation des film dans la perspective de la traduction intersémiotique. Il mettra l'accent sur l'histoire de transpositions ciné-littéraires, sa trajectoire depuis les origines du cinéma, à travers les ciné-romans et les romans adaptés des films. Dans une histoire d'échanges et de dialogues, deux formes de film et deux nouveaux modes d'écriture s'imposent. Entre l'un et l'autre, on assiste à l'apparition du parlant et au renouvelement du roman. Il s'agira ici d'observer comment l'écrivain parvient à créer une tension entre les deux zones du récit dans la création d'une œuvre autonome, dotée d'une résonance propre.

Mots-clés: Cinéma et littérature; novellisation; traduction intersémiotique. 


\section{Referências}

BOURDIEU, Pierre. As regras da arte: gênese e estrutura do campo literário. Trad. Maria Lucia Machado. São Paulo: Companhia das Letras, 1996.

CAMPOS, Haroldo de. Miramar na mira. In: ANDRADE, Oswald de. Memórias sentimentais de João Miramar. São Paulo: Globo, [s. d.].

CARRIÈRE, Jean-Claude. A linguagem secreta do cinema. Trad. Fernando e Benjamim Albagli. Rio de Janeiro: Nova Fronteira, 1995.

CARRIÈRE, Jean-Claude. Meu tio. Trad. Paulo Werneck. São Paulo: Cosac Naify, 2009.

CLERC, Jeanne-Marie. Littérature et cinema. Paris: Nathan, 1993.

CLERC, Jeanne-Marie. La littérature devant les images modernes: cinéma, photographie, télévision. In: BRUNEL, Pierre; CHEVREL, Yves (Dir.). Précis de littérature comparée. Paris: Presses Universitaires de France, 1989.

FUZELLIER, Étienne. Cinéma et littérature. Paris: Cerf, 1964.

JAKOBSON, Roman. Essais de linguistique générale. Trad. Nicolas Ruwet. Paris: Éditions de Minuit, 1963.

VIRMAUX, Alain. Le ciné-roman: un genre nouveau. Paris: Edilig, [s. d.]. 